\title{
Osteopathy for primary headache patients: a systematic review
}

\section{Francesco Cerritelli ${ }^{1-3}$ \\ Eleonora Lacorte ${ }^{4}$ \\ Nuria Ruffini' \\ Nicola Vanacore ${ }^{4}$}

'Clinical-based Human Research Department, Centre for Osteopathic Medicine Collaboration, ${ }^{2}$ Department of Neuroscience, Imaging and Clinical Sciences, ${ }^{3} \mathrm{TTAB}$ - Institute for Advanced Biomedical Technologies, G. D'Annunzio University of Chieti, Pescara, ${ }^{4}$ National Centre for Epidemiology, Surveillance and Health Promotion, National Institute of Health, Rome, Italy
Correspondence: Francesco Cerritelli Clinical-based Human Research Department, Centre for Osteopathic Medicine Collaboration, Onlus, Via Vespucci, I88, Pescara 65I26, Italy Email francesco.cerritelli@gmail.com
This article was published in the following Dove Press journal: Journal of Pain Research

14 March 2017

Number of times this article has been viewed

Objective: This systematic review aimed to assess the efficacy, effectiveness, safety, and tolerability of osteopathic manipulative treatment (OMT) in patients with headache.

Background: Migraine is one of the most common and disabling medical conditions. It affects more than $15 \%$ of the general population, causing high global socioeconomic costs, and the currently available treatment options are inadequate.

Methods: We systematically reviewed all available studies investigating the use of OMT in patients with migraine and other forms of headache.

Results: The search of literature produced six studies, five of which were eligible for review. The reviewed papers collectively support the notion that patients with migraine can benefit from OMT. OMT could most likely reduce the number of episodes per month as well as drug use. None of the included studies, however, was classified as low risk of bias according to the Cochrane Collaboration's tool for assessing risk of bias.

Conclusion: The results from this systematic review show a preliminary low level of evidence that OMT is effective in the management of headache. However, studies with more rigorous designs and methodology are needed to strengthen this evidence. Moreover, this review suggests that new manual interventions for the treatment of acute migraine are available and developing.

Keywords: osteopathic manipulative treatment, tension type headache, pain, migraine, disability

\section{Introduction}

\section{Description of the condition}

Headache is a multicomposite disorder characterized by episodic or recurrent acute pain in the region of the head. The IHS classifies headache as primary, secondary, or of other type. ${ }^{1}$ A recent European study reports a gender-adjusted 1-year prevalence of $78.6 \%$ for any type of headache. ${ }^{2}$ Other forms of headaches include migraine with a $35.3 \%$ prevalence, TTH with a $38.2 \%$ prevalence, chronic headache ( $\geq 15$ days $/$ month) with a $7.2 \%$ prevalence, and $\mathrm{MOH}$ with a $3.1 \%$ prevalence. $^{2}$ Due to its high prevalence, headache has a strong impact on health care programs, policies, and economics. It has also been estimated that $17.7 \%$ of males and $28.0 \%$ of females lost $>10 \%$ of days due to migraine, and that $44.7 \%$ of males and $53.7 \%$ of females lost $>20 \%$ of days due to $\mathrm{MOH}^{2}$ The economic burden of headache was estimated to be a total annual cost of $€ 173$ billion among adults aged $18-65$ years, ${ }^{3}$ with a mean annual cost of $€ 1222$ per person for migraine (95\% CI: $€ 1055-€ 1389$; indirect costs $=93 \%$ ), $€ 303$ for TTH (95\% CI: $€ 230-€ 376$; indirect costs $=92 \%)$, and $€ 3561$ for $\mathrm{MOH}(95 \% \mathrm{CI}$ : $€ 2487-€ 4635$; indirect costs $=92 \%$ ). Guidelines recommend treating chronic headache 
with antidepressants such as amitriptyline, while in case of sporadic headache episodes (up to 10 days per month), pain can be treated with analgesics or NSAIDs. ${ }^{4}$ Additional effective, tolerable, and safe intervention approaches would be extremely useful either in addition to, or as substitutes of, drug therapies.

\section{Brief description of the intervention}

$\mathrm{OM}$ is a nonpharmacological, noninvasive manual medicine, regarded by some as CAM. Osteopathic practitioners use a wide variety of therapeutic manual techniques to improve physiological function and help restore the homeostasis altered by any somatic (body framework) dysfunction (ICD10 code: M99.0-99.9). ${ }^{5}$ The two essential components of OM are 1) the structural assessment for diagnosis and 2) all the different manipulative techniques for the treatment. The aim of the structural assessment is to identify specific somatic dysfunctions. Diagnostic criteria for somatic dysfunctions focus on the tone and possible abnormalities of tissue texture. Areas of asymmetry and misalignment of bony landmarks are also evaluated, along with the quality of motion, balance, and organization. The term OMT currently includes $>20$ types of manual treatments administered by osteopaths. ${ }^{6}$

\section{How the intervention might work}

The possible effect of OMT could be due to two main mechanisms: increasing of the parasympathetic tone, and inhibiting the release of proinflammatory substances. Headache has been shown to be associated with impairment of both the ANS and the specific autonomic nuclei responsible for pain perception and sustained pain. Patients with chronic headache may show peripheral and central sensitization, lack of habituation, ${ }^{7}$ and other phenomena belonging to the so-called pain-matrix. ${ }^{8}$ Underlying dysautonomic symptoms are reported to reduce the release of norepinephrine and to increase the secretion of dopamine and prostaglandins. ${ }^{9}$ Moreover, studies report that subjects having a migraine episode release high levels of proinflammatory agents and serotonin, ${ }^{7,10}$ thus altering the neural autonomic pathways.

Evidence has shown that application of OMT influences the ANS, producing a parasympathetic effect, ${ }^{11-13}$ thus leading to a trophotropic tuning state. ${ }^{13}$ Moreover, OMT seems to be associated with a reduction of proinflammatory substances both in vitro ${ }^{14}$ and in vivo, ${ }^{15,16}$ thus bringing up the hypothesis of OMT having an anti-inflammatory role. Therefore, the use of OMT in the treatment of patients with headache could counterbalance the release of proinflammatory molecules and cause subsequent feedback and feedforward effects on the ANS. ${ }^{17}$ Consequently, a cascade of biological and neurological events could be triggered, potentially based on a rebalance of the abnormal activation of the habituation/ sensitization mechanism, resulting in an overall improvement of clinical outcomes. ${ }^{17}$

\section{Why is it important to perform this review}

Results from clinical controlled trials on OMT for primary and secondary forms of headaches are not conclusive. This review is part of a larger project aiming at establishing the clinical effectiveness of osteopathy in patients with headache and other neurological conditions. The primary objective of this systematic review is to assess the efficacy, effectiveness, safety, and tolerability of OMT in patients with headache.

\section{Methods Types of studies}

Only RCTs and quasi-RCTs were considered eligible. Studies were included if they reported at least one headache-related clinical outcome (eg, response, frequency, pain intensity, headache scores, and use of analgesics). Studies that measured the effectiveness of OMT using standardized and validated PROMs as primary outcome or studies reporting the number of headache days as a secondary outcome within a health care program were also included. Descriptive studies and trials reporting only physiological or laboratory parameters were excluded.

\section{Types of participants}

Studies including patients of any gender, ethnicity, and age with a clinical diagnosis of headache according to any criteria were considered eligible. The accuracy and reliability of the diagnosis and of the diagnostic tools were considered as qualitative parameters. Studies including patients with at least one of the following clinical conditions were excluded: neurodegenerative, cardiovascular, genetic, respiratory, or rheumatologic diseases, and/or psychiatric or psychological disorders.

\section{Types of interventions}

We included all studies investigating any type of OMT performed by an osteopath. Due to the intrinsic clinical variability of manual techniques in terms of magnitude, frequency, and time, no dosage restrictions (frequency and time) were applied. 


\section{Types of comparisons}

Sham therapy, standard care/other treatments, or no treatment were considered as control interventions. We defined as sham interventions all interventions mimicking "true" osteopathic treatment, but modifying at least one aspect considered relevant by the osteopathic theory, such as the diagnosis of somatic dysfunction or the correct location of the area for manual treatment. Standard care or other treatment included pharmacological therapies, relaxation, physical therapies, and so on. "No treatment" required that neither experimental nor standardized treatment could be initiated during the trial period. Trials that only compared different forms of OMT were excluded. Studies including combined manual treatments were excluded. OMT interventions and/or sham treatments could be administered in combination with usual/routine care.

\section{Search methods}

All literature published up to April 2016 was retrieved through a comprehensive systematic search on the following databases: Embase, PubMed Central, ScienceDirect, MEDLINE, Scopus, Web of Science, Google Scholar, the Cochrane Library, chiloras/MANTIS, PubMed Europe, WHO ICTRP, OSTMED.DR, and Osteopathic Research Web. Duplicate records were identified using the EndNOTE software and excluded. Gray literature was also retrieved using the following sources: Web searching, conference proceedings, national trial registers (eg, ClinicalTrials.gov). Details on the search strategy are provided in the Supplementary material.

\section{Types of outcomes}

We considered as primary outcome the MD in number of days with headache per month between study group and control group after at least 4 weeks of treatment.

The secondary outcomes considered herein included the following:

- Safety-related measures, such as number and types of adverse events in both groups

- Headache intensity, quantified through any available measure

- Frequency of analgesic use, calculated with any continuous or rank measures available

- Difference from baseline to end of treatment in the dose of any pharmacological treatment

- Any PROM

- Any reference to economic impact or cost reduction.

Most of these outcomes rely on patient reports, mainly collected in headache diaries. In cases wherein data were available for more than one data point after randomization, the following strategies were applied: data closest to 4 weeks were chosen for the first time period, data closest to 8 weeks were chosen for the second time period, data closest to 3 months were chosen for the third time period, and data closest to 6 months were chosen for the fourth time period.

\section{Selection of studies}

Two reviewers (NR and EL) analyzed the literature retrieved through the search strategies and independently selected the studies pertinent and relevant to the topic of the review. Disagreements were resolved by consensus or by a third reviewer (VN).

The full texts of selected studies were then assessed for inclusion by applying the predefined eligibility criteria.

\section{Data collection and evaluation}

Data extraction was carried out independently by two reviewers. Extracted data included the type of interventions, number of patients, study results, and all other descriptive characteristics reported in the included trials. Where reported details were missing or insufficient, authors were contacted. All data were stored in a specific hard disk, managed only by the two reviewers. Disagreements were discussed and resolved by consensus.

\section{Assessment of RoB in the included studies}

All reviewers independently assessed the methodological quality of the included RCTs using two different tools: the Jadad score ${ }^{18}$ and the Cochrane RoB tool. ${ }^{19}$ Both scores are specifically designed to assess the quality of trials and include specific questions for the identification of potential methodological issues/biases affecting the following key phases: allocation concealment, comparability of groups at baseline, blinding of participants and evaluators, and management of withdrawals/dropouts.

The Jadad score includes three items: allocation, blinding, and description of withdrawals and dropouts. One point is assigned for each item if an accurate and detailed description is provided, while if the item is judged inadequate or incomplete, the point is withdrawn. The highest possible score is five points, and studies scoring less than three points are usually considered as being of low methodological quality.

The Cochrane RoB tool includes five domains: sequence generation, allocation concealment, blinding to personnel, blinding to outcome analysis, and other bias. RoB is assessed 
for each domain according to a three-point scale: low RoB, unclear RoB, and high RoB.

The operational definitions adopted to apply the scoring systems will be provided by the authors upon request. Frequency of agreement and weighted kappa statistics were calculated to measure agreement between the evaluators for both scoring systems.

\section{Measures of treatment effect}

When available, data for continuous variables were reported as MDs, along with their 95\% CIs, while dichotomous outcomes were reported as RRs along with their $95 \%$ CIs. In the case of missing data, authors of the studies were contacted for further information.

\section{Assessment of heterogeneity}

Studies were pooled only in case of significant homogeneity, as assessed with the $I^{2}$ test. The $I^{2}$ value measures the amount of variation between studies attributable to heterogeneity rather than to chance. ${ }^{20}$ Values $\geq 75 \%$ are usually considered as reflecting moderate-to-high heterogeneity, but the statistical significance of $I^{2}$ also depends on the magnitude and direction of the effect as well as the strength of the evidence. Reasons for heterogeneity can be methodological, statistical, or clinical. Clinical heterogeneity was assessed analyzing possible differences across studies in the type of enrolled patients, the type of intervention under investigation and how it was administered, the type of intervention chosen as a comparison and how it was administered, the type of outcome considered, the control event rate/baseline risk, the setting in which the trial was carried out, the comparison conditions, early stopping rules, if present, and the population risk. ${ }^{21}$ Funnel plots were used to test for publication bias, ${ }^{20}$ and in case of nonparametric data, the Duval-Tweedie "trim-andfill" test was also used.22

\section{Data synthesis}

Data from the review were reported according to the PRISMA statement. $^{23}$

A meta-analysis of either dichotomous outcomes or continuous outcomes was carried out whenever possible; where a meta-analysis was not possible, results were presented using summary and descriptive statistics. Weighted MDs as well as effect sizes were calculated. When feasible, subgroup analyses were carried out, stratifying for age classes (adolescent, adult, and elderly), type of headache (chronic vs acute; primary vs secondary), gender, as well as type and frequency of OMT. Meta-analyses were carried out using
Review Manager version 5.2.6, while the remaining statistical analyses were performed using the software R. A $p$-value $<0.05$ was considered as statistically significant.

\section{Results}

A total of 383 records were retrieved through database searches and by hand searching of other sources. An extensive search for gray literature was also carried out, though no additional records were retrieved. After removing duplicates, 138 articles were excluded. An extensive search for gray literature was also carried out, though no additional records were retrieved. Out of the 245 records remaining after removing duplicates, 239 were excluded based on information provided in the titles and/or abstracts. The main reason for exclusion was that some articles did not report original research, but rather provided general information on the management of headache, instructions on the use of some osteopathic techniques in patients with headache, or general information on the possible benefits of OMT. Some abstracts reporting original research were also excluded as they did not meet predefined inclusion criteria.

The full texts of the six remaining studies were retrieved and assessed for inclusion. One further trial was excluded after reading its full text, as it did not report enough information to be included in the review. ${ }^{24}$ Therefore, five studies met the inclusion criteria and were qualitatively assessed ${ }^{25-29}$ (Figure 1).

All included studies were in English. Two trials were carried out in Italy, ${ }^{26,28}$ one was carried out in Germany, ${ }^{29}$ one in Canada, ${ }^{25}$ and one in the USA. ${ }^{27}$ All of the included studies except for one ${ }^{27}$ (four out of five included studies, 80\%) were published after 2006 and were RCTs with a parallel-group design. Two studies compared three groups of subjects randomized to three arms, ${ }^{26,27}$ while the other three studies were designed to compare two groups of subjects randomized to two arms. ${ }^{25,28,29}$

\section{Interventions and comparisons}

All trials considered OMT as their primary intervention. One study considered OMT in association with usual care. ${ }^{26}$ The osteopathic techniques and approaches varied highly across studies, as well as the number of sessions per patient, which ranged from one to eight. The dose, frequency, and length of treatment were also heterogeneous. Details on the professionals administering the treatment (ie, background, experience, and number of professionals recruited) were reported only in two studies. ${ }^{26,29}$

The characteristics of the control groups also widely varied across studies. Two studies ${ }^{26,28}$ used sham therapy, a 


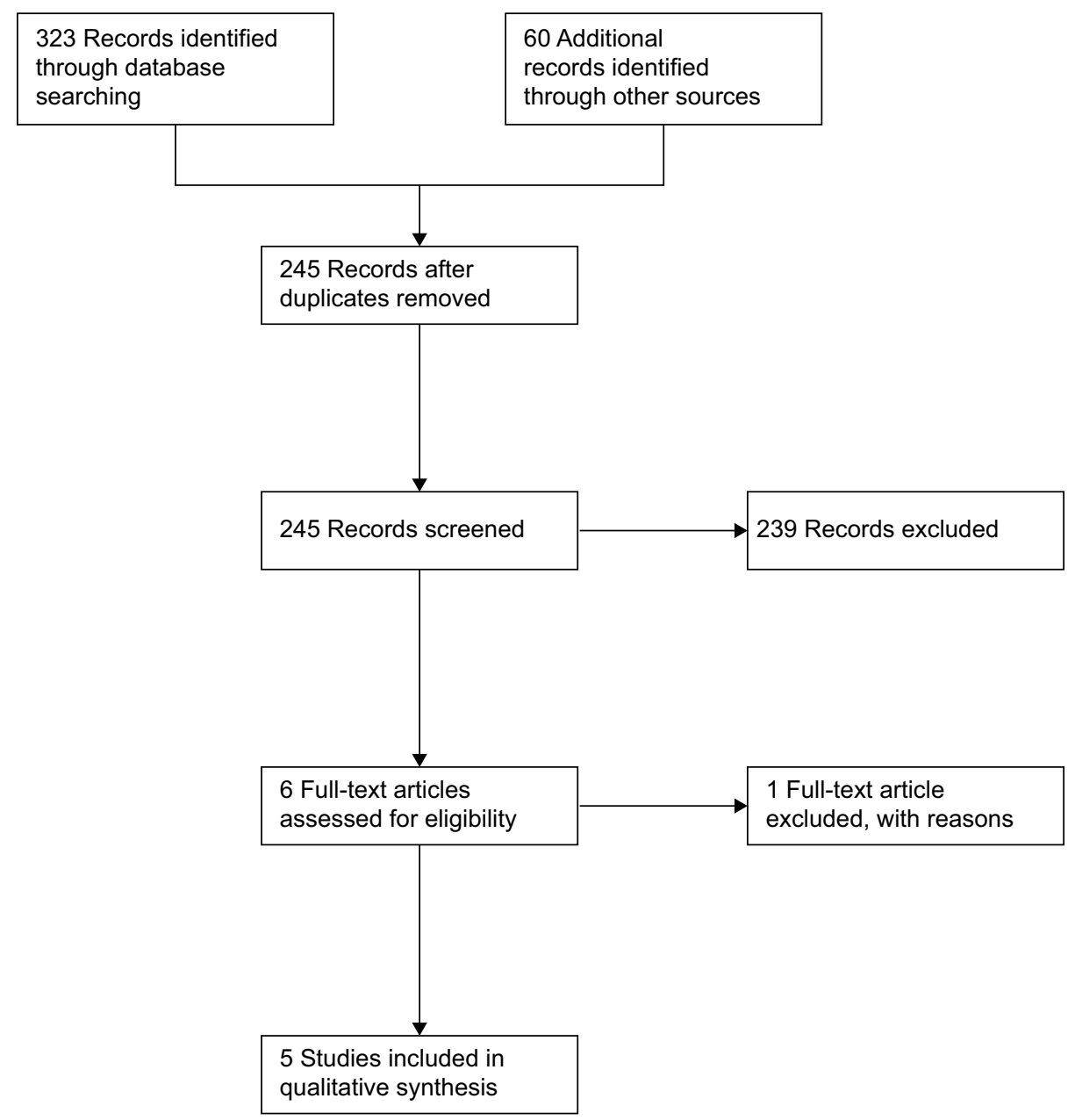

Figure I Flowchart of study selection.

treatment mimicking the primary intervention but without applying any technique; one study ${ }^{25}$ used progressive muscular relaxation; one study ${ }^{27}$ administered either palpatory examination or supine rest sessions; and the last study ${ }^{29}$ used a questionnaire. Osteopathic interventions and control procedures were administered in different settings, ranging from private clinics to public hospitals.

\section{Sample size and length of study}

Overall, included trials enrolled a total of 265 participants (mean: 53, range: 22-105). All included patients were adults (age range: 18-65 years). All trials reported the length of follow-up, which ranged from 9 to 20 months. Rolle et $\mathrm{al}^{28}$ conducted the only study that considered a further follow-up at 3 months.

\section{Outcomes reported}

Four out of five trials reported data on the frequency of headache, which was the outcome we considered as primary for this review.
One of the two trials including three groups ${ }^{26}$ showed that OMT was effective in reducing migraine episodes during 6 months of treatment. It also reported a decrease from eight to six units in the HIT-6 score in the treated group when compared to both the control group and the sham group, in addition to a decrease in migraine episodes, use of drugs, as well as pain and disability scores.

Voigt et $\mathrm{al}^{29}$ reported OMT to be effective in significantly improving pain scores, HRQoL, and working disability in female patients with migraine, but not in reducing days of migraine.

Rolle et $\mathrm{al}^{28}$ reported a significantly lower frequency of headache in the OMT group compared to the control group and proved OMT to be effective in reducing the use of medications over time. No adverse effects were reported in this trial.

Anderson and $\mathrm{Seniscal}^{25}$ reported a significant increase in the number of headache-free days per week in the treated group. No statistically significant differences were observed in the headache degree of improvement and the headache diary rating between groups. 
Hoyt et $\mathrm{al}^{27}$ showed a reduction of headache severity in the treated group, but no changes in EMG parameters.

\section{Description of quality}

Mean interrater reliability in the qualitative assessment using the Jadad score resulted in a kappa value of 0.74 , while the kappa value for the qualitative assessment using the Cochrane RoB tool was 0.68 .

\section{Allocation}

Two studies ${ }^{26,28}$ used a computer-based random-generated list $^{26}$ and coin tossing ${ }^{28}$ as methods of randomization, and both methods were considered at low RoB. Another study used a random-generated table but did not report any further detail. ${ }^{25}$ The remaining studies ${ }^{27,29}$ did not specify the method for randomization.

As for the method used for allocation concealment, one study was considered at high $\mathrm{RoB},{ }^{28}$ as the treating physician also performed randomization, while another ${ }^{26}$ was considered at low $\mathrm{RoB}$, as the process for randomization was performed by an external subject. All other trials did not report enough information to allow for assessment. ${ }^{25,27,29}$

\section{Blinding of participants and personnel}

In three studies, the osteopathic therapists were unblinded to the allocation of participants. ${ }^{26-28}$ Two studies reported no information on the topic. ${ }^{25,29}$

Participants were blinded to treatment in two out of the five included trials. One trial compared OMT with home-based relaxation exercises, thus keeping participants unblinded to the treatment. ${ }^{25}$ One trial explicitly stated that participants were not blinded to the treatment they were receiving, ${ }^{29}$ and another trial did not report details on blinding. ${ }^{27}$ Only one study kept participants blinded to the treatment they were receiving, with only a one-question posttreatment telephone survey administered by a neurologist. ${ }^{26}$

Two studies reported no information on who enrolled participants. ${ }^{26,27}$ One study reported that participants were enrolled by the treating practitioner, ${ }^{25}$ while another study did not provide any further information. ${ }^{28}$ The last study reported having used newspaper advertisements and flyers to recruit patients but did not provide any further details. ${ }^{29}$

\section{Blinding of outcome assessors}

Two studies reported that the investigators who assessed the outcome were blinded to the allocation of participants..$^{25,26}$ The remaining studies did not provide information on the topic. $^{27-29}$

\section{Selective bias}

As protocols were not accessible for any of the included studies, selective bias could not be assessed.

\section{Other bias}

The quality of included studies was further evaluated by considering the presence/absence and adequacy of other reported information such as informed consent, ethical approval, trial registration, data collection, data management, data monitoring committee, access to data, reporting funding source, conflict and declaration of interests, and confidentiality. Two studies reported having requested and obtained informed consent from enrolled participants, ${ }^{25,28}$ while three were rated as unclear, as no details were reported. ${ }^{26,27,29}$ Three out of five studies reported having obtained ethical approval, ${ }^{25,26,29}$ while only one study reported having registered the trial, and only one study provided information on data collection. ${ }^{26}$ Only two studies reported information on the source of funding, ${ }^{26,27}$ and the majority of included studies reported statements from authors declaring to have no conflicts of interests. ${ }^{25,26,28,29}$

None of the included studies reported information on confidentiality, data management, data monitoring committee, and access to data.

\section{Description of adverse events}

Two studies out of five (40\%) collected data on adverse events, ${ }^{26,28}$ stating that none of the participants reported any adverse event/effect attributable to the treatment.

\section{Description of heterogeneity}

A high level of clinical heterogeneity was observed among included studies, with wide variation across studies in the type of considered participants, interventions, and outcomes, as shown in Table 1. Enrolled participants differed in terms of age, disease severity at baseline, and comorbidities. The type of OMT used, its dose and frequency of administration, the length of treatment, the type of therapist performing the treatment, and the setting in which it was administered widely varied across studies. A wide variability was also observed in the type of comparisons used (manual vs non-manual), the way the control intervention was administered (light touch, no intervention, and relaxation exercises), the type of therapist who administered it, as well as the dose and setting. Moreover, none of the included studies reported any information on concomitant treatments.

High heterogeneity was also observed in the type of outcomes considered and in the length of follow-up, which ranged from immediately after treatment up to 6 months. Only 
Table I Main characteristics of the included studies

\begin{tabular}{|c|c|c|c|c|c|c|}
\hline $\begin{array}{l}\text { Author } \\
\text { (year) }\end{array}$ & Outcome measures & $\begin{array}{l}\text { Description of } \\
\text { interventions }\end{array}$ & $\begin{array}{l}\text { Time to } \\
\text { outcome } \\
\text { measurement }\end{array}$ & Population & $\begin{array}{l}\text { Type of } \\
\text { headache }\end{array}$ & $\begin{array}{l}\text { Relevant outcome } \\
\text { results }\end{array}$ \\
\hline $\begin{array}{l}\text { Cerritelli } \\
\text { et al, } 2015^{26}\end{array}$ & $\begin{array}{l}\text { Effectiveness of OMT in } \\
\text { terms of the following: } \\
\text { I) HIT-6 score, 2) days/mo } \\
\text { with migraine, 3) severity } \\
\text { of pain, 4) amount of } \\
\text { rescue medication, 5) } \\
\text { functional disability, and } \\
\text { 6) adverse effects of OMT }\end{array}$ & $\begin{array}{l}\text { OMT ( } \mathrm{n}=35) \text { : Description: } \\
\text { NBT, } 8 \text { sessions ( } 4 \text { weekly, } \\
2 \text { bimonthly, } 2 \text { monthly, } \\
30 \text { min) } \\
\text { Concomitant treatments: } \\
\text { Y, triptans at need } \\
\text { Control I ( } n=35) \text { : sham } \\
\text { OMT } \\
\text { Description: sham OMT, } \\
8 \text { sessions ( } 4 \text { weekly, } 2 \\
\text { bimonthly, } 2 \text { monthly, } \\
30 \text { min) } \\
\text { Concomitant treatments: } \\
\text { Y, triptans at need } \\
\text { Control } 2 \text { ( } n=35 \text { ): usual } \\
\text { care } \\
\text { Description: triptans at need }\end{array}$ & $6 \mathrm{mo}$ & $\begin{array}{l}\mathrm{N}=105 ; \text { age } \\
=38.7 \pm 9.3 \text { years; } \\
\text { male }=34 \%\end{array}$ & $\begin{array}{l}\text { Migraine } \\
\text { (according } \\
\text { to ICHD-II) }\end{array}$ & $\begin{array}{l}\text { Decrease of HIT-6 } \\
\text { score for OMT vs } \\
\text { controls ( } p<0.00 \mathrm{I}) \\
\text { Decrease in days of } \\
\text { migraine for OMT vs } \\
\text { controls ( } p<0.00 \mathrm{I}) \\
\text { Decrease in pain } \\
\text { intensity for OMT vs } \\
\text { controls ( } p<0.00 \mathrm{I}) \\
\text { Decrease in drug } \\
\text { consumption for OMT } \\
\text { vs controls ( } p<0.00 \mathrm{I} \text { ) } \\
\text { Adverse events: none }\end{array}$ \\
\hline $\begin{array}{l}\text { Rolle et al, } \\
2014^{28}\end{array}$ & $\begin{array}{l}\text { Efficacy of OMT in terms } \\
\text { of the following: } \\
\text { I) headache frequency, 2) } \\
\text { headache pain intensity, 3) } \\
\text { over-the-counter } \\
\text { medication use, and 4) HDI }\end{array}$ & $\begin{array}{l}\text { OMT }(n=2 \mathrm{I}) \text { : } \\
\text { Description: NBT, } 4 \text { sessions } \\
\text { (weekly) } \\
\text { Concomitant treatments: } \\
\text { Y, not specified } \\
\text { Control ( } \mathrm{n}=19 \text { ): sham OMT } \\
\text { Description: sham OMT, } 4 \\
\text { sessions (4 weekly) } \\
\text { Concomitant treatments: } \\
\mathrm{Y}, \text { not specified }\end{array}$ & $\begin{array}{l}4 \mathrm{w} \text {; follow-up } \\
\text { at I and } 3 \text { mo }\end{array}$ & $\begin{array}{l}N=40 ; \text { age } \\
=34.5 \pm 12 \text { years; } \\
\text { male }=14 \%\end{array}$ & $\begin{array}{l}\text { Frequent } \\
\text { episodic TTH } \\
\text { (according to } \\
\text { ICHD-III) }\end{array}$ & $\begin{array}{l}\text { Headache frequency: } \\
\text { OMT vs control: } 33 \% \\
\text { decrease }(p<0.00 \mathrm{I}) \\
\text { Pain intensity: } 20 \% \\
\text { reduction within OMT } \\
\text { group compared to } \\
\text { baseline ( } p<0.00 \mathrm{I}) \\
\text { Drug consumption: } 45 \% \\
\text { reduction within OMT } \\
\text { group compared to } \\
\text { baseline ( } p<0.00 \mathrm{I}) \\
\text { Adverse events: none }\end{array}$ \\
\hline $\begin{array}{l}\text { Voigt et al, } \\
2011^{29}\end{array}$ & $\begin{array}{l}\text { Effectiveness of OMT in } \\
\text { terms of the following: } \\
\text { I) HRQoL, 2) pain } \\
\text { intensity, 3) days of } \\
\text { migraine headache, } \\
\text { 4) working disability, } \\
\text { 5) German "Pain } \\
\text { Questionnaire", and 6) } \\
\text { MIDAS, and 7) SF-36 }\end{array}$ & $\begin{array}{l}\text { OMT }(n=2 \mathrm{I}) \text { : } \\
\text { Description: NBT, } 5 \text { sessions } \\
\text { (bimonthly, } 50 \mathrm{~min} \text { ) } \\
\text { Concomitant treatments: } \\
\text { Y, not specified } \\
\text { Control }(\mathrm{n}=2 \mathrm{I}) \text { : no } \\
\text { intervention } \\
\text { Description: not specified }\end{array}$ & $6 \mathrm{mo}$ & $\begin{array}{l}\mathrm{N}=42 ; \text { age } \\
=45 \pm \mathrm{I} \text { I years; } \\
\text { male }=0 \%\end{array}$ & $\begin{array}{l}\text { Migraine } \\
\text { (according } \\
\text { to ICD-I0) }\end{array}$ & $\begin{array}{l}\text { Decrease in pain } \\
\text { intensity (within group): } \\
\text { OMT ( } p<0.05 \text { ), control } \\
(p=0.87) \\
\text { Decrease in days of } \\
\text { migraine (within group): } \\
\text { OMT ( } p=0.31 \text { ); control } \\
\text { ( } p=0.89) \\
\text { Decrease in working } \\
\text { disability (within group): } \\
\text { OMT ( } p=0.06 \text { ); control } \\
\text { ( } p=0.47) \\
\text { Decrease in MIDAS } \\
\text { (within group): OMT } \\
\text { ( } p=0.04 \text { ); control } \\
\text { ( } p=0.76 \text { ) }\end{array}$ \\
\hline $\begin{array}{l}\text { Anderson } \\
\text { and Seniscal, } \\
2006^{25}\end{array}$ & $\begin{array}{l}\text { Effects of OMT in terms of } \\
\text { the following: } \\
\text { I) headache frequency, 2) } \\
\text { headache intensity, 3) HD, } \\
\text { and 4) } \mathrm{HI}\end{array}$ & $\begin{array}{l}\text { OMT }(n=\mid 4) \text { : } \\
\text { Description: protocol, } 3 \\
\text { sessions (weekly) } \\
\text { Concomitant treatments: } \\
\text { Y, PMR } \\
\text { Control ( } n=12 \text { ): PMR } \\
\text { Description: relaxation } \\
\text { exercise ( } / \text { day, } 20 \mathrm{~min} \text { ) }\end{array}$ & $6 w$ & $\begin{array}{l}N=26 ; \text { age }= \\
N A ; \text { male = NA }\end{array}$ & $\begin{array}{l}\text { Any type } \\
\text { of TTH } \\
\text { (according } \\
\text { to IHS 2004) }\end{array}$ & $\begin{array}{l}\text { Decrease in headache } \\
\text { frequency (free days } / \mathrm{w} \text { ): } \\
\text { OMT vs control } \\
(p=0.016)\end{array}$ \\
\hline
\end{tabular}


Table I (Continued)

\begin{tabular}{|c|c|c|c|c|c|c|}
\hline $\begin{array}{l}\text { First auth } \\
\text { year }\end{array}$ & Outcome measures & $\begin{array}{l}\text { Description of } \\
\text { interventions }\end{array}$ & $\begin{array}{l}\text { Time to } \\
\text { outcome } \\
\text { measurement }\end{array}$ & Population & $\begin{array}{l}\text { Type of } \\
\text { headache }\end{array}$ & $\begin{array}{l}\text { Relevant outcome } \\
\text { results }\end{array}$ \\
\hline $\begin{array}{l}\text { Hoyt et al, } \\
1979^{27}\end{array}$ & $\begin{array}{l}\text { Effects of OMT in terms of } \\
\text { the following: } \\
\text { I) headache pain intensity } \\
\text { and 2) EMG }\end{array}$ & $\begin{array}{l}\text { OMT }(n=10) \text { : } \\
\text { Description: protocol, } \\
\text { I session (same day, } \\
\text { I0 min) } \\
\text { Concomitant treatments: NA } \\
\text { Control I ( } n=6) \text { : OE } \\
\text { Description: protocol, } \\
\text { I session (same day, I0 min) } \\
\text { Concomitant treatments: NA } \\
\text { Control } 2 \text { ( } n=6) \text { : rest } \\
\text { Description: supine } \\
\text { Concomitant treatments: NA }\end{array}$ & IAT & $\begin{array}{l}\mathrm{N}=22 ; \text { age }= \\
\mathrm{NA} ; \text { male }=\mathrm{NA}\end{array}$ & $\begin{array}{l}\text { Chronic } \\
\text { muscle } \\
\text { tension } \\
\text { headache }\end{array}$ & $\begin{array}{l}\text { Decrease in headache } \\
\text { intensity (worst } \\
\text { headache } \\
\text { improvement): OMT } \\
\text { vs control ( } p=0.07 \text { ) } \\
\text { Pain intensity: among } \\
3 \text { groups: } F=I 7.16 \\
\text { ( } p<0.00 \mathrm{I}) \text {; reduction } \\
\text { within OMT group } \\
\text { compared to baseline } \\
(p<0.00 \mathrm{I})\end{array}$ \\
\hline
\end{tabular}

Abbreviations: OMT, osteopathic manipulative treatment; HIT-6, headache impact test-6; NBT, need-based treatment; PMR, progressive muscular relaxation exercises; OE, osteopathic evaluation; HD, headache diary; HDI, headache disability index; HI, headache index; EMG, electromyography; IAT, immediately after treatment; NA, not available; TTH, tension type headache; ICHD, International Classification of Headache Disorders; ICD, International Classification of Diseases; IHS, International Headache Society; Y, yes; mo, months; w, weeks; min, minutes; MIDAS, Migraine Disability Assessment questionnaire; SF-36, Short Form-36.

one study reported results during the follow-up period. ${ }^{28}$ Two studies did not report information on included subjects. ${ }^{25,27}$

The type of headache was also heterogeneous across studies. Included trials enrolled patients with different conditions, such as chronic migraine, episodic TTH or episodic migraine, chronic muscle-tension headache, and any type of TTH. This is further confirmed by the different classification codes adopted (ICHD-II, ICHD-III, ICD-10 ${ }^{30}$ ). A consistent variability was also observed in the pathophysiological considerations used across the included studies.

Only one study calculated the sample size before enrolling participants. ${ }^{26}$ Included studies can, therefore, be considered as having substantial heterogeneity in terms of study design and characteristics and, subsequently, in their overall RoB.

\section{Discussion}

Results showed that several different types of OMT have been used with the objective of preventing and treating primary headache. This systematic review showed that the evidence supporting the effectiveness of OMT in decreasing pain intensity and frequency, as well as in reducing disability in patients with headache, is still preliminary and of low methodological quality. The overall quality of included evidence is also too low to draw conclusions on the effectiveness of OMT in improving any other considered outcome. Quality assessment showed that the majority of studies were at high or unclear RoB, with most of the studies having several methodological limitations in the management of confounding factors, the random sequence generation, and having a high risk of incomplete reporting of outcome data. The comparability of results was also affected by the heterogeneity in the criteria adopted for the selection of participants; moreover, the inadequate and inaccurate description of interventions and comparisons affected the reproducibility and reliability of results. The majority of trials did not report adverse events with a structured methodology, and unreported details were pointed out.

\section{Study limitations}

Every attempt was made to include all relevant studies, though the risk of having missed some other pertinent or relevant publication cannot be ruled out. We used strict eligibility criteria to increase the external validity of results and their generalizability to different settings. Several studies investigated the comparative effectiveness of different preventive strategies and therapeutic programs, but results from these studies should be cautiously considered when planning interventions aimed at the prevention and management of headache. A further limitation of included studies is their consideration of heterogeneous populations. This limits the generalizability of results and affects the interpretation of results. Moreover, selection bias cannot be ruled out, as no behavioral or neuropsychological assessment was performed at baseline and/or at enrollment, thus leaving the possibility of having missed some psychological and/or psychiatric conditions.

Specific types of headaches are likely to respond in different ways and extents to the same treatment and should therefore be studied individually. The heterogeneity of included studies, along with the high RoB and the imprecision of results, made it impossible to perform a quantitative analysis and/or meta-analysis of the results for any of the predefined outcomes. 


\section{Consideration (or recommendation) for future research}

Future studies should be carefully designed and include proper control intervention and randomization strategies. Participants should be enrolled based on the ICHD to ensure proper comparability of samples across studies. An intention-to-treat analysis should be performed, and appropriate strategies for the management of missing data should be considered. Attention should be paid to the accuracy and precision of results, as both were relevant issues affecting results in several of the included studies that did not provide data as mean values along with CIs. The sample size should also be calculated, to ensure that the study had adequate statistical power. A complete and adequate reporting of results should also be guaranteed.

\section{Conclusion}

Consequences of headache constitute a major burden in the worldwide population, causing significant costs and resource expenditures. Currently, only a few studies have investigated interventions aimed at either the secondary prevention or the management of headache. This systematic review suggests that OMT can reduce future pain episodes and related disability in adults with headache. Further population-based studies with a more rigorous design are needed to provide stronger evidence supporting the effectiveness of interventions aimed at the treatment and secondary prevention of primary headaches.

\section{Acknowledgments}

The authors sincerely thank Dr Jorge Esteves for reviewing the article. No financial support has been received for this review.

\section{Author contributions}

Francesco Cerritelli conceptualized and designed the study, analyzed the data, and wrote the article. Eleonora Lacorte performed the initial search, reviewed all included studies, analyzed the data, and wrote the article. Nuria Ruffini performed the initial search, reviewed all included studies, and wrote the article. Nicola Vanacore wrote the article. All authors contributed toward data analysis, drafting and critically revising the paper and agree to be accountable for all aspects of the work.

\section{Abbreviations}

$\mathrm{TTH}$, tension-type headache; $\mathrm{MOH}$, medication overuse headache; CI, confidence interval; NSAIDs, nonsteroidal anti-inflammatory drugs; OM, osteopathic medicine; CAM, complementary and alternative medicine; OMT, osteopathic manipulative treatment; ANS, autonomic nervous system;
PROM, patient-reported outcome measure; WHO ICTRP, World Health Organization's International Clinical Trial Registry Platform; RoB, risk of bias; MD, mean difference; RR, relative risk; PRISMA, Preferred Reporting Items for Systematic Reviews and Meta-Analyses; HIT-6, headache impact test-6; HRQoL, Health-related quality of life; EMG, electromyography. ICHD, International Classification of Headache Disorders; ICD, International Classification of Diseases; IHS, International Headache Society; RCTs, randomized controlled trials

\section{Disclosure}

The authors report no conflicts of interest in this work.

\section{References}

1. Headache Classification Committee of the International Headache Society (IHS). The International Classification of Headache Disorders, 3rd edition (beta version). Cephalalgia. 2013;33(9):629-808.

2. Steiner TJ, Stovner LJ, Katsarava Z, et al. The impact of headache in Europe: principal results of the Eurolight project. $J$ Headache Pain. 2014; $15: 31$.

3. Linde M, Gustavsson A, Stovner LJ, et al. The cost of headache disorders in Europe: the Eurolight project. Eur J Neurol. 2012;19(5): 703-711.

4. Diener HC, Brune K, Gerber WD, Gobel H, Pfaffenrath V. Behandlung der migraneattacke und migraneprophylaxe. Empfehlungen der Deutschen Migrane- und Kopfschmerzgesellschaft. [Treatment of migraine attacks and migraine prophylaxis: recommendations of the German Migraine and Headache Society]. Med Monatsschr Pharm. 1998;21(2):30-39. German.

5. Cicchitti L, Martelli M, Cerritelli F. Chronic inflammatory disease and osteopathy: a systematic review. PLoS One. 2015;10(3):e0121327.

6. Ward RC HR, Jerome JA, Jones JM, et al; Association AO. Foundations for Osteopathic Medicine. 2nd ed. Baltimore, MD: Lippincott Williams \& Wilkins; 2002.

7. Strassman AM, Raymond SA, Burstein R. Sensitization of meningeal sensory neurons and the origin of headaches. Nature. 1996;384(6609): 560-564.

8. Coppola G, Di Lorenzo C, Schoenen J, Pierelli F. Habituation and sensitization in primary headaches. J Headache Pain. 2013;14:65.

9. Peroutka SJ. Migraine: a chronic sympathetic nervous system disorder. Headache. 2004;44(1):53-64.

10. Aurora SK, Wilkinson F. The brain is hyperexcitable in migraine Cephalalgia. 2007;27(12):1442-1453.

11. Giles PD, Hensel KL, Pacchia CF, Smith ML. Suboccipital decompression enhances heart rate variability indices of cardiac control in healthy subjects. J Altern Complement Med. 2013;19(2):92-96.

12. Henley CE, Ivins D, Mills M, Wen FK, Benjamin BA. Osteopathic manipulative treatment and its relationship to autonomic nervous system activity as demonstrated by heart rate variability: a repeated measures study. Osteopath Med Prim Care. 2008;2:7.

13. Ruffini N, D'Alessandro G, Mariani N, Pollastrelli A, Cardinali L, Cerritelli F. Variations of high frequency parameter of heart rate variability following osteopathic manipulative treatment in healthy subjects compared to control group and sham therapy: randomized controlled trial. Front Neurosci. 2015;9:272.

14. Zein-Hammoud M, Standley PR. Modeled osteopathic manipulative treatments: a review of their in vitro effects on fibroblast tissue preparations. J Am Osteopath Assoc. 2015;115(8):490-502.

15. Licciardone JC, Kearns CM, Hodge LM, Bergamini MV. Associations of cytokine concentrations with key osteopathic lesions and clinical outcomes in patients with nonspecific chronic low back pain: results from the OSTEOPATHIC Trial. J Am Osteopath Assoc. 2012;112(9):596-605. 
16. Licciardone JC, Kearns CM, Hodge LM, Minotti DE. Osteopathic manual treatment in patients with diabetes mellitus and comorbid chronic low back pain: subgroup results from the OSTEOPATHIC Trial. J Am Osteopath Assoc. 2013;113(6):468-478.

17. D’Alessandro G., Cerritelli F., Cortelli P. Sensitization and interoception as key neurological concepts in osteopathy and other manual medicines. Front Neurosci.2016;10:100.

18. Jadad AR, Moore RA, Carroll D, et al. Assessing the quality of reports of randomized clinical trials: is blinding necessary? Control Clin Trials. 1996;17(1):1-12.

19. Higgins JP. Cochrane Handbook for Systematic Reviews of Interventions Version 5.1.0. Oxford: The Cochrane Collaboration; 2011.

20. Higgins JP, Thompson SG, Deeks JJ, Altman DG. Measuring inconsistency in meta-analyses. BMJ. 2003;327(7414):557-560.

21. Gagnier JJ, Moher D, Boon H, Beyene J, Bombardier C. Investigating clinical heterogeneity in systematic reviews: a methodologic review of guidance in the literature. BMC Med Res Methodol. 2012;12:111.

22. Duval S, Tweedie R. Trim and fill: a simple funnel-plot-based method of testing and adjusting for publication bias in meta-analysis. Biometrics. 2000;56(2):455-463.

23. Moher D, Liberati A, Tetzlaff J, Altman DG. Preferred reporting items for systematic reviews and meta-analyses: the PRISMA statement. PLoS Med. 2009;6(7):e1000097.
24. Hanten WP, Olson SL, Hodson JL, Imler VL, Knab VM, Magee JL. The effectiveness of CV-4 and resting position techniques on subjects with tension-type headaches. J Man Manip Ther. 1999;7(2):64-70.

25. Anderson RE, Seniscal C. A comparison of selected osteopathic treatment and relaxation for tension-type headaches. Headache. 2006;46(8):1273-1280.

26. Cerritelli F, Ginevri L, Messi G, et al. Clinical effectiveness of osteopathic treatment in chronic migraine: 3 -armed randomized controlled trial. Complement Ther Med. 2015;23(2):149-156.

27. Hoyt WH, Shaffer F, Bard DA, et al. Osteopathic manipulation in the treatment of muscle-contraction headache. J Am Osteopath Assoc. 1979;78(5):322-325.

28. Rolle G, Tremolizzo L, Somalvico F, Ferrarese C, Bressan LC. Pilot trial of osteopathic manipulative therapy for patients with frequent episodic tension-type headache. J Am Osteopath Assoc. 2014;114(9): 678-685.

29. Voigt K, Liebnitzky J, Burmeister U, et al. Efficacy of osteopathic manipulative treatment of female patients with migraine: results of a randomized controlled trial. J Altern Complement Med. 2011;17(3): 225-230.

30. Headache Classification Subcommittee of the International Headache Society. The International Classification of Headache Disorders: 2nd ed. Cephalalgia 2004;24(Suppl 1):1-160. 


\section{Supplementary material}

Search strategy: keywords used

((()((()(((((osteopath* AND manipulat* AND (treatment OR therapy))) OR Manipulation, Osteopathic[MeSH]) OR ((osteopath*AND medicine $))$ ) OR ((manual*AND treatment*))) OR ((spinal AND manipulat*))) OR Manipulation, Spinal[MeSH]) OR ((visceral AND manipulat*))) OR (((crani* OR crani* AND sacral OR cranio *sacral) AND osteopat* AND (manipulat* OR manual OR treatment)))) OR (((craniosacral OR cranio-sacral OR cranio sacral)))) OR ((osteopath* AND diagnosis))) OR ((osteopath* AND palpat*))) OR ((osteopath* AND principle* AND practice*)) AND ((headache AND (disease* OR disorder*)))))

The Journal of Pain Research is an international, peer reviewed, open access, online journal that welcomes laboratory and clinical findings in the fields of pain research and the prevention and management of pain. Original research, reviews, symposium reports, hypothesis formation and commentaries are all considered for publication
The manuscript management system is completely online and includes a very quick and fair peer-review system, which is all easy to use. Visit http://www.dovepress.com/testimonials.php to read real quotes from published authors. 